\title{
Biomaterial implants in the treatment of oncology: a review
}

\author{
Saba Maanvizhi ${ }^{1}$, Vijayakumar Arumugam Ramamurthy ${ }^{2 *}$, \\ Athithan Velan ${ }^{3}$, Pugazhenthan Thangaraju ${ }^{4}$
}

\author{
${ }^{1}$ Sri Ramachandra Faculty of Pharmacy, Sri Ramachandra Institute of Higher Education and Research, (DU), Porur, \\ Chennai, Tamil Nadu, India \\ ${ }^{2}$ Department of Pharmacology, Faculty of Pharmacy, Sree Balaji Medical College and Hospital Campus, BIHER, \\ Chennai, Tamil Nadu, India \\ ${ }^{3}$ School of Medical Laboratory Technology, Mother Theresa Post Graduate and Research, Institute of Health Sciences, \\ Puducherry, India \\ ${ }^{4}$ Department of Pharmacology, AIIMS Raipur, Chhattisgarh, India
}

Received: 11 May 2021

Revised: 04 June 2021

Accepted: 05 June 2021

\section{*Correspondence:}

Dr. Vijayakumar Arumugam Ramamurthy, Email: marunthiyal2013@gmail.com

Copyright: (C) the author(s), publisher and licensee Medip Academy. This is an open-access article distributed under the terms of the Creative Commons Attribution Non-Commercial License, which permits unrestricted non-commercial use, distribution, and reproduction in any medium, provided the original work is properly cited.

\begin{abstract}
In globally, cancer is a second leading disease next to cardiovascular diseases in non-communicable diseases, which affect the all ages, sex, social status, ethnicity and primary cause of illness related death. Traditionally, systemic delivery drug systems like chemotherapy via oral capsule, injections of nanoparticles/micro particles, immunotherapy and others, which can inhibit or halt the progression of tumors. The short half-life of drugs which cannot achieve the targeted dose level to the tumor site and not able to target desired cell and commonly produces the organ toxicity. Recently, researchers have been attempting to direct delivery agents for cancer therapy. One of the best methods is a local therapy system, which deliver the drug directly via implantable procedure and it's achieved the maximum concentration of the desire drug at the tumor site, non-target systemic exposure and minimize the organ toxicity to the patients. Biomaterial implants are widely used in the local concurrent delivery of chemotherapy and anti-angiogenic agents, local delivery of poly-chemotherapy, gene therapy as an alternative to drug delivery, scaffolds for cancer immunotherapy and polymerbased composites of drug molecules. There are different types of polymers like poly anhydride poly [bis ( $\mathrm{p}$-carboxyphenoxy) propane-sebacic acid] copolymer [p(CPP:SA)], fatty acid dimer-sebacic acid copolymer (FAD-SA), poly (lactic-co-glycolic acid) copolymer (PLGA), poly ( $\varepsilon$-caprolactone) (PCL), poly (glycerol monostearate-cocaprolactone), alginate and silica, used in successively cancer therapy. In order to minimize the risk of unwanted side effect of different types of biomaterials implants, it's biocompatible to reduce the ability to elicit the inflammatory effect to the implanted area or the site. Therefore, the key role of choosing the appropriate and biocompatible implants to particular therapy is an indispensable. This should be validated with respect to risk benefit ratio in case of cancers. Biomaterial based implant local delivery systems provide more versatile and tailorable approach to against treatment of different types of the cancer.
\end{abstract}

Keywords: Adverse reactions, Biomaterials, Cancer, Hazard, Implants, Alginate, Silica

\section{INTRODUCTION}

According to the National Cancer Registry Programme Report 2020 (NCRP) which was published by Indian
Council of Medical Research (ICMR) and National Centre for Disease Informatics and Research (NCDIR) about 13.9 lakhs of cancer cases was estimated and which would likely to increase to about 15.7 lakhs by $2025 .{ }^{1}$ The various 
treatment options available for cancer includes surgery, radiation therapy, chemotherapy, immunotherapy, targeted therapy, hormone therapy, stem cell transplant and precision medicine. ${ }^{2}$ The difficulty in both diagnosis and treatment of cancer is due to the complex nature of the cancer like drug resistance developed by cancer cells, penetration of the drug being obstructed by the increasing levels of interstitial fluid pressure (IFP) etc., with the advancement of bioengineering tools and their incorporation in the cancer research paved the way for completely newer techniques for the treatment of cancer. ${ }^{3,4}$ In addition to it, these tools also promoted the efficacy of the classical treatment procedures like chemotherapy and surgery. ${ }^{5,6}$

One of the important contributions of the bioengineering is the biomaterials in which various novel strategies are being applied for the treatment of cancer. Biomaterials can be of natural or synthetic origin which are used in various medical applications for supporting, enhance or replace damaged tissue or biological function and various fields of science like medicine, biology, physics, chemistry, tissue engineering and material science are also combined with the modern field of biomaterials. ${ }^{7}$ The different clinical applications of engineered materials include controlled drug delivery systems, gene therapies, development of scaffolds for tissue engineering, replacement and augmentation of body tissues, and surgical devices. ${ }^{8}$ Based on their utilization in different implant applications biomaterials are classified mainly into five types such as natural biomaterials, biopolymers, metals and their alloys, composites and bio-ceramics. When compared to the metals and ceramics polymers show versatility, which is the main reason for being widely used. ${ }^{9}$ The various examples for natural biodegradable polymeric materials are proteins such as silk, fibrin, collagen, gelatin and polysaccharides like as alginate, starch, hyaluronic acid derivatives and chitosan. ${ }^{10,11}$ Though natural polymers are potential candidates they have few limitations like difficulty to control their degradation rates and mechanical properties, ability to induce an immune response. ${ }^{12}$ In case of synthetic polymers biocompatibility is considered to be a huge challenge and hence synthetic biodegradable polymers plays a significant role due to their ability of overcoming the effects of synthetic polymer like inflammation and scarring. ${ }^{13}$ Some of the examples of synthetic biodegradable polymers are poly (glycolicacid) (PGA), poly (lactic acid) (PLA) and their copolymers such as poly (lactic-co-glycolide) (PLGA) or poly (L-lactic acid) (PLLA), polydioxanone (PDO), poly (caprolactone) (PCL) and the copolymers of glycolide and trimethylenecarbonate. ${ }^{14,15}$ This review focuses on the various polymers which are used for making different group of biomaterial implants for the treatment of cancer.

\section{METHODS}

Polyanhydride poly [bis (p-carboxy-phenoxy) propanesebacic acid] copolymer (p(CPP:SA))
It is widely used for the delivering of anticancer drugs in the form of an implantable device and the biocompatibility was found to be non-toxic. ${ }^{16}$ By modifying the ratio of carboxy phenoxy propane (CPP) and sebacic acid (SA) the degradation rate can be controlled. An implantable device (Gliadel@) made of (p(CPP:SA)) is commercially available for the treatment of brain glioblastoma, which is approved by the $U S$ Federal Food and Drug Administration (FDA, USA) for treating high grade malignant gliomas and recurrent glioma multiforme (GBM) in added to the surgical procedures. ${ }^{17,18}$ The heat of fusion value $(\Delta \mathrm{H})(\mathrm{p}(\mathrm{CPP}: \mathrm{SA}))$ found to be decreased from the value of 36.6 to $2.0 \mathrm{Cal} / \mathrm{g}$ when the $\mathrm{CPP}$ was added up to $40 \%$ whereas the $\Delta \mathrm{H}$ value found to be increasing when the value is up to $26.5 \mathrm{Cal} / \mathrm{g}$ while CPP is further added. The $\mathrm{p}(\mathrm{CPP}: \mathrm{SA})$ comprising of the ratio as 60:40 is found to have a low molecular weight of about 6400 but with high tensile strength of about $981 \mathrm{MPa}$. It is found to be one of the most successful polyanhydride copolymers which undergoes erosion at a constant rate. ${ }^{19,20}$ By increasing the concentration of CPP the erosion velocity of $\mathrm{p}(\mathrm{CPP}: \mathrm{SA})$ gets decreased. The erosion zones of $\mathrm{p}(\mathrm{CPP}: \mathrm{SA})$ are found to be separated by erosion fronts from the non-eroded polymer and these erosion fronts will move to the centre from the surface of matrix at a constant velocity. ${ }^{21}$

\section{Poly (lactic-co-glycolic acid) copolymer (PLGA)}

Poly - (lactic acid) (PLA) and poly - (glycolic acid) (PGA) are synthetic biodegradable polyesters are being used as monofilaments and absorbable sutures, since early 1970s. ${ }^{22,23}$ Drug delivery, surgical and medical devices, tissue engineering are some of the different applications of PLGA owing to its nature of non-toxic, bio-degradability and biocompatibility. ${ }^{24,25}$ USFDA has also approved PLGA for various purposes. Organic solvents are required for formulation with PLGA, because of its comparatively hydrophobic nature. ${ }^{26,27}$ PLGA has very good solubility in different kinds of solvents like ethyl acetate, acetone, tetrahydrofuran whereas the solubility is poor for the pure forms of polylactic and polyglycolic acid. Hence, encapsulation of water soluble or water-insoluble drugs can done using this polymer. ${ }^{28}$ PLGA is obtained by different proportions of the lactic acid and glycolic acid and it is found to be a linear aliphatic copolymer. The synthesis of PLGA involves polymer having molecular weight ranging from 10,000 to $200,000 \mathrm{~g} / \mathrm{mol}$ and diverse ratios of lactic acid and glycolic acid. ${ }^{29}$ PLGA could be made either as an amorphous form or crystalline form. It was found that when the lactic acid is less than $70 \%$ the polymer is said to be in amorphous form. ${ }^{30}$ An amorphous form provides uniform dispersion of the payload in the polymer matrix. Hence, it is very much suitable for the drug release and also it exhibits low mechanical strength. ${ }^{31}$

\section{Poly (E-caprolactone) (PCL)}

PCL is found to be chemically comprising of repeating units of hexanoic acid $(\mathrm{C} 6 \mathrm{H} 10 \mathrm{O} 2) \mathrm{n}$ and it can be also 
called as 6-caprolactone polymer or 2-oxepanone homopolymer. ${ }^{32}$ The melting temperature (Tm) of PCL ranges around $332-337 \mathrm{~K}$ and glass transition temperature
( $\mathrm{Tg}$ ) of about $213 \mathrm{~K}$, because of the relatively low melting point it allows to easily producing of drug delivery systems and scaffolds. ${ }^{33}$

Table 1: Structure of the polymers.

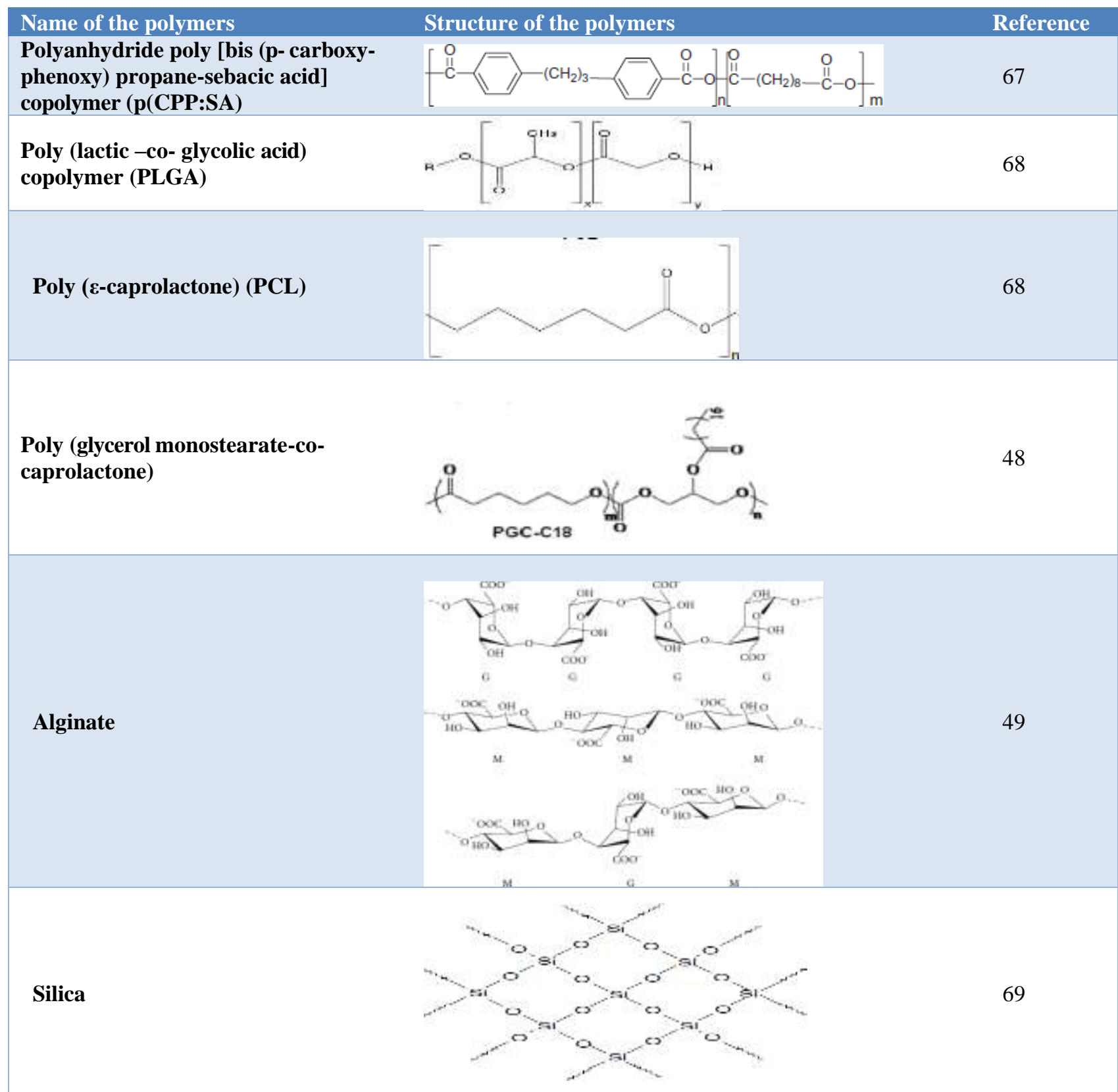

The synthesis of PCL involves ring-opening polymerization of $\varepsilon$-caprolactone which proceeds by different mechanisms like anionic, cationic and radical or coordination and also one of the non-hazardous polymers. ${ }^{34}$ The solubility of PCL is found to insoluble in petroleum ether, ethyl alcohol and water. Similarly, in solvents like acetone, acetonitrile, 2-butanone, dimethylformamide, ethyl acetate the solubility is low whereas in solvents like benzene, carbon tetrachloride, chloroform, cyclohexanone, dichloromethane, toluene, and 2-nitropropane the solubility is high. ${ }^{35-39}$

The PCL chains will move freely at the body temperature, since the amorphous chains becomes rubbery at ambient conditions and this will ultimately result in the increase in permeability of the body metabolites being replaced into the body. ${ }^{40}$ The PCL chain fragments will take longer time for degradation by the hydrolysis by enzymes because of the presence of ester bonds per monomer in a less 
frequently manner and hence, it makes the polymer more stable in comparison to polylactides but biodegradable. It is found that in the biological media with the presence of a constantly changing interstitial fluid the complete degradation of the polymer generally takes about 2-3 years. ${ }^{41-43}$ Hence, the degradation rate is influenced by the $\mathrm{pH}$ of the medium and when compared to the acidic environment the degradation rate is rapid in alkaline environment. ${ }^{44}$ The polymer provides desirable interfacial characteristics and surfaces for the tissue because of its adaptability of surface roughness and hydrophilicity. ${ }^{45}$ Since, the degradation rate of PCL is slow, it is found to be a polymer of choice in the long-term drug delivery and it also has another advantage of being compatible with different group of drugs particularly drugs which are lipophilic in nature. ${ }^{46}$

\section{Poly (glycerol monostearate-co-caprolactone)}

The polymer has an advantage of attaching different functional groups which enables it to modify its ability for different healthcare applications like imaging, drug delivery systems, targeted delivery of drugs and also allows to being responsive to the stimulation from the environment (like change in $\mathrm{pH}$ ). Different structures like $3 \mathrm{D}$ constructs, particles and fibres can be processed by employing this. It was found that, when the hydroxyl group of the glycerol is not free and being coupled with a group like benzyl alcohol then the poly (glycerol-cocaprolactone) copolymer backbone will not degrade significantly taking at least 6 months on exposing to a phosphate buffered solution maintained at $37^{\circ} \mathrm{C} .{ }^{47}$ Hence, in case of a functionalized polymer cast films the drug release kinetics is said to be diffusion controlled. When compared to the unmodified polymer functionalization of polymer by a lipophilic side chain prolonged the drug release kinetics promisingly from the solvent-cast polymer film. ${ }^{48}$

\section{Alginate}

Some of the brown seaweeds like Laminaria hyperborea, Laminaria digitata, Laminaria japonica are the sources for alginate which can isolated by the extraction of these sea weeds. ${ }^{49}$ Hence, they contain lot of impurities like heavy metals, endotoxins and other ingredients, which needs to be removed before their use. The composition of alginate involves a sequence of $\beta$-D-mannuronic acid (M) and $\alpha$-Lguluronic acid $(\mathrm{G})$ which are linked by a $1 \rightarrow 4$ linkage. ${ }^{49}$ The choice of sea weed and also their age which is used as a source determines the relative proportion of $\alpha-\mathrm{L}$ guluronate $(\mathrm{G})$ and $\beta$-D-mannuronate $(\mathrm{M})$ and the molecular weight ranges from 32 to $400 \mathrm{~kg} / \mathrm{mol} .^{50,51}$ The ratio of $M$ and $G$ affects different factors like viscoelasticity, swelling and transmittancy of the alginate gel membranes. ${ }^{52,53}$

The toxicity of alginate is found to be very low and is also biocompatible. ${ }^{54}$ Alginates are widely used because of their ability of being soluble at alkaline and neutral conditions by the presence of carboxyl groups which becomes charged when the $\mathrm{pH}$ increases more than 3-4. Alginate is found to be one of the preferable polymers especially in the conditions of modified drug release or protecting the drug from getting degraded in the stomach $\mathrm{pH}$ and get absorbed in the intestinal tract. Alginate is made as a satisfying biomaterial for drug delivery systems with these advantages. ${ }^{55}$ The alginate gels will become harder and brittle when the $\alpha$-L-guluronic acid (G) content is very high. Hence, the physical and mechanical stability is determined based on the $\alpha$-L-guluronic acid $(\mathrm{G})$ content. However, ethylene diamine tetraacetic acid (EDTA) or sodium citrate can be used in order to revert back the above process. ${ }^{56}$

\section{Silica}

Silica also called as silicon dioxide $\left(\mathrm{SiO}_{2}\right)$ consists of a structure involving repeating units of $\mathrm{SiO}_{4}$ in the form of tetrahedrons. The partial ionic character in silica is created by the larger covalent radii of the silica and oxygen atom than the bond length of $0.162 \mathrm{~nm}$ between $\mathrm{Si}-\mathrm{O}$ atoms. ${ }^{57}$ The important properties of silica with respect to in vivo drug delivery includes the in the presence of aqueous environment its nature of degrading into silicic acid exactly like in vivo conditions, membranes and micro-nano particles can be easily processed using silica, can be used for biosensing (photonic properties) and surface area being very huge such as up to $800 \mathrm{~m}^{2} / \mathrm{g} .{ }^{58-64}$ The various forms in which silica can be used are synthetic silica (prepared by modification of sol-gel chemistry), freshly synthesized silica also. Bioactive glass monoliths and xerogels can be created by processing of the Sol-gel produced silica. The release kinetics of silica xerogel solids can be modified by altering the parameters such as temperature or gelation time which makes xerogels prominent for drug delivery. ${ }^{65}$ Bioactive glass has the ability of promoting the bonding to both soft and hard tissue by forming a carbonate hydroxyapatite layer once there is a contact with the physiological fluids. ${ }^{66}$ The structure of the polymers was tabulated in Table 1.

\section{CONCLUSION}

The perfect solution for the successful treatment of cancer lies on the developing of efficacious drugs and proper drug delivery system, which provides delivering of drugs selectively on the particular target cancer cells. This can be achieved through biomaterials - based implants, which help to overcome the obstacles which are faced by the systemic delivery of the drugs and ultimately resulting in better therapeutic outcomes. The drugs which are failed to provide successful outcome can be repurposed with the recent advancement of the local delivery devices. The important point to be considered in the local delivery of drugs are more desirable for localized lesions, however, the case of tumors which are spread and poorly localized, then the most appropriate approach will be a combination comprising of both systemic and local delivery. In future, novel strategies and methods in biomaterial implants 
should be developed in such a way that instead of existing technology like delivery of drugs using only one method combinational therapy should be adopted.

In summary, the biomaterial implants are playing a crucial role in the treatment of cancer and will also act as an indispensable device for all the new generation therapeutics.

\section{Funding: No funding sources}

Conflict of interest: None declared

Ethical approval: Not required

\section{REFERENCES}

1. Report of National Cancer Registry Programme 2020. 2020. https://www.ncdirindia.org/All_Reports/ Report_2020/default.aspx. Accessed on 2 November 2020.

2. Type of cancer treatment. National Cancer Institute. https://www.cancer.gov/aboutcancer/treatment/types. Accessed on 2 November 2020.

3. Holohan C, Van Schaeybroeck S, Longley DB, Johnston PG. Cancer drug resistance: an evolving paradigm. Nat Rev Cancer. 2013;13:714-26.

4. Goel S, Duda DG, Xu L, Munn LL, Boucher Y, Fukumura D et al. Normalization of the vasculature for treatment of cancer and other diseases. Physiol Rev. 2011;91:1071-121.

5. Zamboni WC, Torchilin V, Patri AK, Hrkach J, Stern $\mathrm{S}$, Lee $\mathrm{R}$, et al. Best practices in cancer nanotechnology: perspective from NCI nanotechnology alliance. Clin Cancer Res.2012;18:3229-41.

6. Nguyen QT, Tsien RY. Fluorescence-guided surgery with live molecular navigation--a new cutting edge. Nat Rev Cance. 2013;13:653-62.

7. https://www.nibib.nih.gov/science-education/sciencetopics/biomaterials. Accessed on 12 November 2020.

8. Kulinets I. Biomaterials and their applications in medicine. Elsevier, Amsterdam, Netherlands. 2015.

9. Kasprzak KS, Sunderman FW Jr, Salnikow K. Nickel carcinogenesis. Mutat Res. 2003;533:67-97.

10. Marijnissen WJ, van Osch GJ, Aigner J, van der Veen SW, Hollander AP, Verwoerd-Verhoef HL et al. Alginate as a chondrocyte-delivery substance in combination with a non-woven scaffold for cartilage tissue engineering. Biomaterials. 2002;23:1511-17.

11. Park H, Choi B, Hu J, Lee M. Injectable chitosan hyaluronic acid hydrogels for cartilage tissue engineering. Acta Biomater. 2013;9:4779-86.

12. Lee $\mathrm{CH}$, Singla A, Lee Y. Biomedical applications of collagen. Int J Pharm. 2001;221:1- 22.

13. Fournier E, Passirani C, Montero-Menei CN, Benoit JP. Biocompatibility of implantable synthetic polymeric drug carriers: focus on brain biocompatibility. Biomaterials. 2001;24:3311-31.

14. Poole-Warren L, Martens P, Green R. Biosynthetic Polymers for Medical Applications. Elsevier, Amsterdam. 2016.
15. Wang Z, Li N, Li R, Li Y, Ruan L. Biodegradable intestinal stents: A review. Progress Nat Sci Mater Int. 2014;24:423-32.

16. Walter KA, Cahan MA, Gur A, Tyler B, Hilton J, Colvin OM, et al. Interstitial taxol delivered from a biodegradable polymer implant against experimental malignant glioma. Cancer Res. 1994;54:2207-12.

17. Westphal M, Hilt DC, Bortey E, Delavault P, Olivares $\mathrm{R}$, Warnke et al. A phase 3 trial of local chemotherapy with biodegradable carmustine (BCNU) wafers (Gliadel wafers) in patients with primary malignant glioma. Neuro Oncol. 2003;5:79-88.

18. Kleinberg LR, Weingart J, Burger P, Carson K, Grossman SA, Li K, et al. Clinical course and pathologic findings after Gliadel and radiotherapy for newly diagnosed malignant glioma: implications for patient management. Cancer Invest. 2004;22:1-9.

19. Dang W, Daviau T, Brem H. Morphological characterization of polyanhydride biodegradable implant Gliadel ${ }^{\circledR}$ during in vitro and in vivo erosion using scanning electron microscopy. Pharm Res. 1996;13:683-91.

20. Leach KJ, Mathiowitz E. Degradation of doublewalled polymer microspheres of PLLA and $\mathrm{P}$ (CPP:SA)20:80. I. In vitro degradation. Biomaterials. 1998;19:1973-80.

21. Göpferich A, Tessmar J. Polyanhydride degradation and erosion. Adv Drug Deliv Rev. 2002;54:911-31.

22. Khatri K, Goyal AK, Vyas SP. Potential of nanocarriers in genetic immunization. Recent Pat Drug Deliv Formul. 2008;2:68-82.

23. Horton CE, Adamson JE, Mladick RA, Carraway JH. Vicryl synthetic absorbable sutures. Am Surg. 1974;40:729-31.

24. Astete CE, Sabliov CM. Synthesis and characterization of PLGA nanoparticles. J Biomater Sci Polym Ed. 2006; 7:247-89.

25. Chaubal M. Polylactides/ glycolides - excipients for injectable drug delivery and beyond. Drug Deliv Tech. 2002;2:34-36.

26. Biondi M, Ungaro F, Quaglia F, Netti PA. Controlled drug delivery in tissue engineering. Adv Drug Deliv Rev. 2008;60:229-42.

27. Houchin ML, Topp EM. Chemical degradation of peptides and proteins in PLGA: a review of reactions and mechanisms. J Pharm Sci. 2004;97:2395-404.

28. Zhang K, Tang X, Zhang J, Lu W, Lin X, Zhang Y, et al. PEG-PLGA copolymers: their structure and structure-influenced drug delivery applications. J Control Release. 2014;183:77-86.

29. Parent M, Nouvel C, Koerber M, Sapin A, Maincent $\mathrm{P}$, Boudier A. PLGA in situ implants formed by phase inversion: critical physicochemical parameters to modulate drug release. J Control Release. 2013;172:292-304.

30. Jain RA. The manufacturing techniques of various drug loaded biodegradable poly (lactide-co- glycolide) (PLGA) devices. Biomaterials. 2000;21:2475-90.

31. Habraken WJ, Wolke JG, Mikos AG, Jansen JA. Injectable PLGA microsphere/calcium phosphate 
cements: physical properties and degradation characteristics. J Biomater Sci Polym Ed. 2006; 17:1057-74.

32. Labet M, Thielemans W. Synthesis of polycaprolactone: a review. Chem Soc Rev. 2009;38:3484-504.

33. Kariduraganavar MY, Kittur AA, Kamble RR. Polymer Synthesis and Processing. In: Kumbar S, Laurencin CT, Deng M (ed). Natural and Synthetic Biomedical Polymers, 1st edn. Elsevier Science, Boston. 2014;1-31.

34. Hoskins JN, Grayson SM. Synthesis and degradation behavior of cyclic poly ( $\varepsilon$-caprolactone). Macromolecules. 2009;42:6406-13.

35. Azimi B, Nourpanah P, Rabiee M, Arbab S. Poly ( $\varepsilon-$ caprolactone) fiber: An overview. J Engineered Fibers Fabrics. 2014;9:74-90.

36. Sezer UA, Aksoy EA, Hasirci V, Hasirci N. Poly ( $\varepsilon-$ caprolactone) composites containing gentamicinloaded $\beta$-tricalcium phosphate/ gelatin microspheres as bone tissue supports. J Appl Polym Sci. 2012;127:1-8.

37. Sezer UA, Arslantunali D, Aksoy EA, Hasirci V, Hasirci N. Poly ( $\varepsilon$-caprolactone) composite scaffolds loaded with gentamicin-containing $\beta$-tricalcium phosphate/gelatin microspher es for bone tissue engineering applications, J Appl Polym Sci. 2014;131:1-11.

38. Hernán Pérez de la Ossa D, Ligresti A, Gil-Alegre ME, Aberturas MR, Molpeceres J, Di Marzo V, et al. Poly$\varepsilon$-caprolactone microspheres as a drug delivery system for cannabinoid administration: development, characterization and in vitro evaluation of their antitumoral efficacy. J Control Release. 2012;161:927-32.

39. Tong SY, Wang Z, Lim PN, Wang W, Thian ES. Uniformly-dispersed nanohydroxapatite- reinforced poly ( $\varepsilon$-caprolactone) composite films for tendon tissue engineering application. Mater Sci Eng C Mater Biol Appl. 2017;70(Pt 2):1149-55.

40. Mark HF. Encyclopedia of Polymer Science and Technology. John Wiley \& Sons, Inc., New Jersey. 2014.

41. Díaz E, Sandonis I, Valle MB. In vitro degradation of poly ( $\varepsilon$-caprolactone)/ nHA composites. J Nanomaterials. 2014:1-8.

42. Gleadall A, Pan J, Kruft MA, Kellomäki M. Degradation mechanisms of bioresorbable polyesters. Part 1. Effects of random scission, end scission and autocatalysis. Acta Biomater. 2014;10:2223-23.

43. Gleadall A, Pan J, Kruft MA, Kellomäki M. Degradation mechanisms of bioresorbable polyesters. Part 2. Effects of initial molecular weight and residual monomer. Acta Biomater. 2014;10:2233-40.

44. Hernández AR, Contreras OC, Acevedo JC, Moreno LGN. Poly ( $\varepsilon$-caprolactone) degradation under acidic and alkaline conditions. Am J Polym Sci3:70-75, 2013.

45. Xu FJ, Wang ZH, Yang WT. Surface functionalization of polycaprolactone films via surface- initiated atom transfer radical polymerization for covalently coupling cell-adhesive biomolecules. Biomaterials. 2010;31:3139-47.

46. Wang X, Wang Y, Wei K, Zhao N, Zhang S, Chen J. Drug distribution within poly ( $\varepsilon-$ caprolactone) microspheres and in vitro release. J Mater Process Technol. 2009;209:348-54.

47. Wolinsky JB, Ray WC, Colson YL, Grinstaff MW. Poly (carbonate ester)s Based on units of 6hydroxyhexanoic acid and glycerol. Macromolecules. 2007;40:7065-8.

48. Wolinsky JB, Liu R, Walpole J, Chirieac LR, Colson YL, Grinstaff MW. Prevention of in vivo lung tumor growth by prolonged local delivery of hydroxycamptothecin using poly(ester-carbonate)collagen composites. J Control Release. 2010;144:280-7.

49. Lee KY, Mooney DJ. Alginate: properties and biomedical applications. Prog Polym Sci. 2012;37:106-26.

50. Draget KI, Smidsrod O, Skjak-Braek G. Alginates from algae. In: Steinbuchel EA, Rhee SK (ed) Polysaccharides and Polyamides in the Food Industry: Properties, Production and Patents. Wiley- VCH Verlach GmbH, Weinheim, Germany. 2005;1-30.

51. Tonnesen HH, Karlsen J. Alginate in drug delivery systems. Drug Dev Ind Pharm. 2002;28:621-30.

52. Draget KI, Stokke BT, Yuguchi Y, Urakawa H, Kajiwara K. Small-Angle X-ray Scattering and Rheological Characterization of Alginate Gels. 3. Alginic Acid Gels. Biomacromolecules. 2003;4:166168.

53. Inukai, M, Yonese M. Effects of charge density on drug permeability through alignate gel membranes. Chem Pharm Bull. 1999;47:1059-63.

54. Ching SH, Bansal N, Bhandari B. Alginate gel particles-A review of production techniques and physical properties. Crit Rev Food Sci Nutr. 2017;57:1133-52.

55. Cardoso MJ, Costa RR, Mano JF. Marine Origin Polysaccharides in Drug Delivery Systems. Mar Drugs. 2016;14:34.

56. Machida-Sano I, Matsuda Y, Namiki H. A novel harvesting method for cultured cells using iron- crosslinked alginate films as culture substrates. Biotech Appl Biochem. 2010;55:1-8.

57. Bergna H, Roberts W. Colloidal Silica. Boca Raton: CRC Pres., 2005.

58. Canham LT, Reeves CL, King DO, Branfield PJ, Crabb JG, Ward CL. Bioactive polycrystalline silicon. Adv Mater. 1996;8:850-2.

59. McInnes S, Graney S, Khung YL, Voelcker NH. Porous silicon microparticles as an alternative support for solid phase DNA synthesis. Proc. SPIE. 2006;6036:445-54.

60. Meade SO, Sailor MJ. Microfabrication of freestanding porous silicon particles containing spectral barcodes. Phys Stat Sol (RRL). 2007;1:R713. 
61. Wu EC, Park JH, Park J, Segal E, Cunin F, Sailor MJ. Oxidation-triggered release of fluorescent molecules ordrugs from mesoporous $\mathrm{Si}$ microparticles. ACS Nano. 2008;2:2401-2409.

62. Alvarez SD, Derfus AM, Schwartz MP, Bhatia SN, Sailor MJ. The compatibility of hepatocytes with chemically modified porous silicon with reference to in vitro biosensors. Biomaterials. 2009;30:26-34.

63. Palestino G, Agarwal V, Aulombard R, Pérez E, Gergely C. Biosensing and protein fluorescence enhancementby functionalized porous silicon devices. Langmuir. 2009;24:13765-71.

64. Canham L. Color of Porous silicon. In: Canham LT (ed). Handbook of Porous Silicon. Springer, Cham. 2014;255-62.

65. Prokopowicz M, Przyjazny A. Synthesis of sol-gel mesoporous silica materials providing a slow release of doxorubicin. J Microencapsul. 2007;24:682-701.
66. Lenza RF, Jones JR, Vasconcelos WL, Hench LL. In vitro release kinetics of proteins from bioactive foams. J Biomed Mater Res A. 2003;67:121-9.

67. Domb AJ, Gallardo CF, Langer R. Poly (anhydrides) based on aliphatic -aromatic diacids. Macromolecules. 1989;22(8):3200-04.

68. Song R, Murphy M, Li C, Ting K, Soo C, Zheng Z. Current development of biodegradable polymeric materials for biomedical applications. Drug Design, Development and Therapy. 2018;12: 3117-45.

69. Kupiec K, Konieczka P, Namieśnik J. Characteristics, Chemical Modification Processes as well as the Application of Silica and its Modified Forms. Critical Reviews in Analytical Chemistry. 2009;39(2):60-9.

Cite this article as: Maanvizhi S, Vijayakumar AR, Velan A, Thangaraju P. Biomaterial implants in the treatment of oncology: a review. Int J Basic Clin Pharmacol 2021;10:886-92. 